\title{
Offering HIV testing to pregnant women increased test uptake but not anxiety
}

\author{
Simpson WM, Johnstone FD, Boyd FM, et al. Uptake and acceptability of antenatal HIV testing: randomised controlled trial of \\ different methods of offering the test. BMJJan 24 1998;316:262-7.
}

\section{Question}

Which methods of offering voluntary HIV testing to pregnant women increase test uptake (ie, number of women who take the test) and acceptability?

\section{Design}

Randomised controlled trial.

\section{Setting}

Hospital antenatal clinic in Edinburgh, UK.

\section{Patients}

3505 pregnant women who had their first clinic visit from May 1996 to February 1997. Women were excluded from the study if they were known to be HIV positive or had language difficulties. A total of 3024 women (86\%) participated.

\section{Intervention}

Women were allocated to 1 of 4 intervention groups, which varied by how HIV testing was offered: an HIV specific leaflet with comprehensive $(\mathrm{n}=519)$ or minimal discussion with a midwife $(\mathrm{n}=495)$; or a "blood tests" leaflet with comprehensive $(\mathrm{n}=521)$ or minimal discussion with a midwife $(\mathrm{n}=495)$; or to the control group (usual care with no offer of testing, verbal or written information unless requested) $(n=994)$. The HIV specific leaflet described the benefits and disadvantages of testing, HIV transmission, meaning of test results, and insurance. The "blood tests" leaflet described blood tests and summarised the information in the HIV specific leaflet. The comprehensive discussion protocol covered the main points in the HIV specific leaflet, emphasising the benefits of testing, whereas the minimal protocol was a short check that the women had understood the leaflet. Consultations were done by 10 midwives who were trained in the 2 discussion protocols.

\section{Main outcome measures}

HIV test uptake (verified by laboratory reports), satisfaction with the consultation, and anxiety (6 items from the Spielberger State Trait Anxiety Inventory).

\section{Main results}

Test uptake was higher among women in each of the 4 intervention groups compared with women in the control group $(\mathrm{p}<0.001)$ (table), but did not differ among the intervention groups. Groups did not differ for satisfaction with the consultation or anxiety level.

\section{Conclusions}

Direct offers of HIV testing increased test uptake among pregnant women but neither increased anxiety nor decreased satisfaction with a clinic consultation. Test uptake did not differ for 4 interventions which used combined written and verbal information which varied in comprehensiveness.

HIV test uptake by pregnant women after offers of testing (4 interventions) $v$ no direct offer of testing*

\begin{tabular}{|c|c|c|c|c|}
\hline \multicolumn{2}{|c|}{ Intervention - direct offers of testing } & $\begin{array}{l}\text { No direct } \\
\text { offer }\end{array}$ & $\begin{array}{l}R B I \\
(95 \% C I)\end{array}$ & $\begin{array}{l}N N T \\
(C I)\end{array}$ \\
\hline $\begin{array}{l}\text { Blood tests leaflet and } \\
\text { minimal discussion }\end{array}$ & $36.2 \%$ & $5.5 \%$ & $\begin{array}{l}554 \% \\
\text { (394 to } 767)\end{array}$ & $\begin{array}{l}4 \\
(3 \text { to } 4)\end{array}$ \\
\hline $\begin{array}{l}\text { Blood tests leaflet and } \\
\text { comprehensive } \\
\text { discussion }\end{array}$ & $37.0 \%$ & $5.5 \%$ & $\begin{array}{l}569 \% \\
(407 \text { to } 786)\end{array}$ & $\begin{array}{l}4 \\
(3 \text { to } 4)\end{array}$ \\
\hline $\begin{array}{l}\text { HIV specific leaflet and } \\
\text { minimal discussion }\end{array}$ & $34.5 \%$ & $5.5 \%$ & $\begin{array}{l}524 \% \\
\text { (371 to } 729)\end{array}$ & $\begin{array}{l}4 \\
(3 \text { to } 4)\end{array}$ \\
\hline $\begin{array}{l}\text { HIV specific leaflet and } \\
\text { comprehensive } \\
\text { discussion }\end{array}$ & $31.6 \%$ & $5.5 \%$ & $\begin{array}{l}471 \% \\
\text { (330 to } 660)\end{array}$ & $\begin{array}{l}4 \\
(3 \text { to } 5)\end{array}$ \\
\hline
\end{tabular}

*Abbreviations defined in glossary; RBI, NNT, and CI calculated from data in article.

Source of funding: NHS Research and Development Health Technology Assessment Programme.

For correspondence: $\operatorname{Dr} W$ M Simpson, Department of Obstetrics and Gynaecology, Centre for Reproductive Biology, University of Edinburgh, Edinburgh EH3 9EWUK. Fax +44 (0)131229 2408.

\section{Commentary}

The rate of vertical transmission of HIV can be reduced with antiretroviral treatment during pregnancy and by avoiding breast feeding. Despite the clear advantages of knowing one's HIV status, wide variation in antenatal HIV testing policies and practices remain. The number of infants born each year infected with HIV is rising. This concern is reflected in a new report which recommends that HIV testing be offered to all pregnant women, ${ }^{1}$ a conclusion which is supported by the findings of Simpson et al.

The authors used an experimental design and a large sample. The findings support the introduction of a universal offer of HIV testing to pregnant women to increase uptake without an apparent increase in anxiety or dissatisfaction. The offer of testing was made after appropriate preparation and discussion-factors identified as important in other studies. ${ }^{2}$ Womens' anxiety and satisfaction were measured immediately after consultation when they might be expected to respond positively as a result of the interaction. Women's feelings of anxiety and dissatisfaction might increase with time, however, especially with the receipt of test results. The study did not address this aspect of HIV testing.

The results of this study are relevant to healthcare providers involved in preconception and antenatal care. Test uptake was affected by which midwife offered the test, indicating that despite the research protocol there were differences in the manner in which consultations took place. These findings emphasise the importance of effective communication which is situationally appropriate. Future studies should identify those qualities which most enhance this process and nurses and midwives caring for childbearing women should be educated to ensure they can discuss HIV infection in pregnancy in a well informed and unbiased manner. Susan Dover, RN, RM, MMed Sci Senior Lecturer School of Women's Health Studies University of Central England Birmingham, UK

1 Royal College of Paediatrics and Child Health. Reducing mother to child transmission of HIV infection in the United Kingdom. London: RCPCH, 1998 .

2 Jones S, Sadler T, Low N, et al. BMJ 1998;316: 272-3. 